Document downloaded from:

http://hdl.handle.net/10251/34995

This paper must be cited as:

Lloret Romero, MN. (2011). Outsourcing as a change management tool in libraries and documentation centers. The Bottom Line: Managing Library Finances. 24(1):73-79. doi:10.1108/08880451111142132.

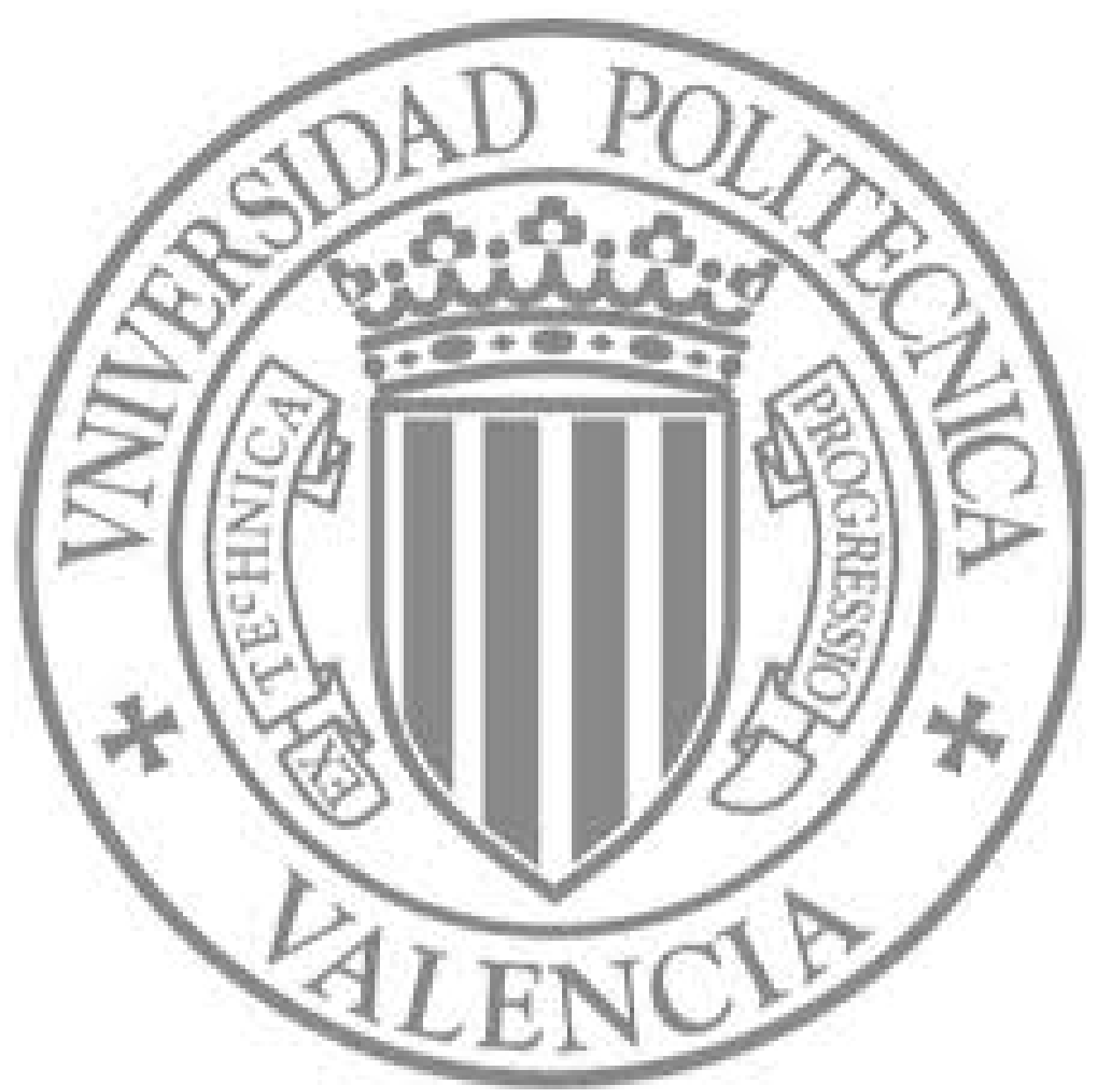

The final publication is available at

http://dx.doi.org/10.1108/08880451111142132

Copyright Emerald 


\title{
Outsourcing as a Change Management Tool in Libraries and Documentation Centers
}

\begin{abstract}
Outsourcing is a tool that has been used in companies for decades. However, it took much longer for this tool to be implemented in libraries and documentation centers especially since they are eminently public entities at an international level. The use of such services has only increased in recent years and has been especially heightened by the economic crisis in all areas of the aforementioned centers. However, it is important to understand the basis of this type of tool in order to look beyond the fiscal and economic benefits and attempt to see the possibilities provided by the use of this type of services for improving the dynamics of organizations and even creating new professional profiles within the organization itself. The outsourcing of services need not always lead to a loss of knowhow, and when working from the heart of the organization it is a tool that can even be used to support a culture of change and the revitalization of organizations less likely to change.
\end{abstract}

Keywords: Outsourcing, externalization, change management, contracting out, human resource management in libraries, subcontracting.

\section{Introduction}

The technological, economic and sociological challenges of the information society are demanding the development of new ways to manage human resources in organizations which allow for a greater degree of flexibility leading to innovation and the strengthening of competitiveness. Consequently, there is a need to adapt to the demands of society with services that in many cases are not performed by the entity itself due to a lack of specialized resources within the organization.

Generally, in recent years the discussion of whether to use outsourcing has been based on economic factors and to a lesser extent the ability to assimilate technological changes and the need for the specialization of the organization. Therefore, the trend has now reserved and the "bigger is better" philosophy accepted since the 50s which led to the creation of large companies that expanded worldwide reaching a high level of diversification and a comprehensive control of the processes linked to production, was overturned.

These organizations are difficult to manage using traditional models based on vertical and hierarchal functional management structures since they are very bureaucratic and outdated, preventing organizational flexibility, entrepreneurial creativity, innovation and the development of competitive models.

But what does outsourcing really mean? If a definition is sought to encompass everything that can be outsourced, it could be concluded that outsourcing is the "service performed within an organization by external employees to create a transfer or assignment of knowledge to functional areas of the organization".

The terms outsourcing, externalization and subcontracting or contracting out are used interchangeably to define a management tool designated by a work area or activity to be managed by another external company called an outsourcer (also referred to as service provider) which specializes in the service required.

Outsourcing can also be defined as the externalization of certain functional areas and the assignment of their management to external service providers. Handy (2000) defines outsourcing as "the contracting out of those functions not considered to form part of the core business of the organization" and uses the term "core" to refer to organization's vital business activities and functions. This is far from the current contracting out of services by means of outsourcing since it is increasingly more common for these services to be performed in relation to the entities' core business and even in the epicenter of the organization. In fact in some cases services are undertaken by a consulting firm specializing in executive and management posts. There are many cases in which all the management positions of a recently established center are outsourced until the center is actually put into operation, the aim being to reduce learning and implementation time through the use of expert staff who are able to make the center advance much more rapidly than if new employees were hired. There are even more cases of outsourcing services which include the most technical tasks of the centers such as cataloguing, digitization, sorting, system integration and migration, etc. However, upon analyzing the type of services where outsourcing truly contributes to a philosophy of change, it 
is where outsourcers are involved with the management and decision-making activities of an organization. If an attempt is made to observe their effect on the philosophy of change in organizations and on the basis of the 7 basic rules of the philosophy of change, the way in which these services are of aid in each case is as follows:

\section{Outsourcing and the seven rules of change in organizations}

Many organizations and especially public institutions do not renew their staff regularly, thus it is possible to encounter organizations where the average age of the employees has gotten higher as the entity has gotten older. Although such entities are acknowledged for their prestige and experience, there is a clear lack of new ways of thinking which enable the organization to advance, above all in technological areas where innovation and change are extremely transient. Therefore, a mixed staff is needed where the knowledge of the organization and processes held by employees who have been with the company since its foundation is combined with the new knowledge and ways of understanding processes held by new recruits. This leads directly to a change in the values of the organization since the incorporation of new ideas in process management and the incorporation of technologies allowing for a more cooperative environment can end up creating an organizational culture with renewed values, always safeguarding the initial core values of the organization and including the new values generated from the incorporation of new ways of working.

\section{Strategic planning}

One of the cornerstones of change management is the shift towards management by means of strategic planning. Strategic planning is based on the creation of working modules that allow the results to be valued and assessed by parts of a whole. Outsourcing services are very useful for strategic planning given that the outsourced service is measured individually and externally taking into consideration that the company is contracted to achieve certain initially agreed upon results. Consequently, once the services have been completed it is simple to assess whether these results have been achieved. This assessment is extendable to other departments in the organization which have not been outsourced through a comparison of results which can give rise to ongoing improvements in the organization-wide results. However, in some cases this assessment has to be handled carefully because it may cause the organization's internal staff to feel threatened. To assure that this does not happen, it is recommendable for the outsourcing team to be formed by both internal and external staff and for the management of these teams to be fully aware of the need to create a corporate culture so that everyone can improve the organization together.

\section{Marketing of services}

Nowadays, the visibility of the services offered is vital for organizations, and often simply redesigning the image of the services offered by the center can cause a new impression on the end-user. In this case there are many centers that contract outsourcing service providers to redesign their corporate image, to promote awareness, to provide website maintenance and updating services, as well as customer assistance services, and above all, in relation to the 2.0 web network, to carry out all types of animation services in social networks such as Facebook, Twitter etc. This type of work requires dedication and knowledge of the media which in many cases does not exist within the organization itself. Furthermore, although such expertise may exist, it is common for specialists in this type of services to use the synergies of different customers to generate traffic in the network which an individual working for a single entity would find very difficult to generate.

\section{Profitability}

Profitability is always prioritized where outsourcing is considered. However, if approached from the perspective of change, the use of these services alone does not give rise to a short-term financial improvement. If an approach of this type is taken for contracting purposes, it is certain that following a number of years, no long-term profitability will be evidenced. While analyses show that many of the services performed at a loss within the organization would not give rise to losses in the short-term if outsourced, where a study of the organizations' direct and indirect costs has not been performed, it may even be the case that having such services performed externally is not profitable for the organization. In these cases, the option of outsourcing can simply involve a use of resources for services which are required to be offered in the organization and which cannot be eliminated immediately. In most cases, the information centers are non-profit institutions where profitability does not lead to an increase in income but 
rather the improved use of resources since this profitability makes it possible to offer more services with the same resources. In many cases outsourcing is the beginning of a change in the institutions' mentality regarding costs and usually involves a new way of analyzing the services they wish to give and why they should be given. Without this type of subcontracting, in many cases these institutions do not even consider the cost of certain of the services they perform. Only analyzing the costs of the possible outsourcing of services provides companies with vital information for taking decisions regarding the services to which more resources should be allocated either internally or by means of outsourcing.

Another reason for outsourcing is the prioritization of certain services whose profitability is usually very high, particularly where trained specialized staff is required and the time required to train such employees might be too lengthy, meaning that the associated internal costs would be impossible to bear. This type of activities is clearly a candidate for outsourcing.

\section{Improvement in human resource management}

Experts have different viewpoints on this matter given that although outsourcing involves the inclusion on staff teams of temporary employees who do not share the institution's philosophy; it also involves the inclusion of new ideas that might lead the group which the outsourcer joins to work in a new way. This type of relationship between teams is the best way to motivate change but it must have been implemented in a strict manner and both the management of the centers and the team which the outsourced employees are to join should have their tasks and responsibilities very clear so that the internal staff does not consider the new employees to be a threat but rather an aid to their daily jobs. In this regard, the role of middle management is vital. The decision to outsource is often taken by senior management and middle management is only notified once the employees have already been outsourced, which in many cases leads them to take a defensive position against the new employees. For the outsourced services to function properly, it is essential for middle managers who will be responsible for coordinating tasks and assessing work to feel involved in decisions regarding when and why these tasks are to be outsourced, to assess the advantages of this option for their departments over hiring internal staff, and to determine how the full team can be assessed following the hiring of external staff.

\section{Communication channels.}

One of the keys to changes in organizations is the creation of clear and transparent communication channels that enable the actual activity carried on in the institution to be communicated. In many cases the use of outsourcing might appear to be clearly negative since the introduction of external teams may not appear to support the organization's internal communication. This is not actually true since the basis of outsourcing is the continuous monitoring of the requested targets and results. Therefore, management meetings must be held and reports must be drafted which provide knowledge of the activity carried out. For this purpose, working groups are created in the organization to assess this work, and these serve as an aid to any internal management policy regarding the entities' communication.

\section{Social impact}

The process of change in an organization whose purpose is clearly to provide services is to have a greater social impact and improve the quality of the community to which its services are offered. It is difficult to determine whether outsourcing improves this impact. However it has been evidenced that where service is improved as a result of this outsourcing, the community's perception of this service is much better, which in turn gives rise to a higher impact on society. It is essential that it be taken into consideration that if the services which are contracted are to be provided to end users, they can both positively and negatively affect the end user's viewpoint of the center. Therefore, it is very important for the outsourced services to be managed keeping in mind how visible they are to end users. In many cases, the services contracted out by the organization are internal but in other cases customer services provided outside of office hours and distribution services, etc. are outsourced and this does directly affect the users' perception of the services. Accordingly, the outsourced services have to be managed taking into account the impact they may have outside the organization to assure that this impact will be positive for our community.

\section{The ten reasons outsourcing is considered to be a tool of change}


1) - The reduction and operational control of costs improves the institution's profitability giving rise to an improved use of resources.

2) -By capitalizing on the core business of the organization, working processes and their management are improved giving rise to management by objectives and to the introduction of strategic planning in the organization.

3) -Advantages of access to world-class competition are generated enabling the best services to be provided to users, which in turn increases the visibility of the institution on a community level.

4) - If resources are reused for other activities there is an increased offer of services, which in turn has an effect on the organization and on the users.

5) - The availability to the organization of external resources gives rise to new working approaches that can create a new way of working within the organization.

6) -The use of outsourcing allows for the benefits of reengineering processes to be accelerated, thus improving the quality of services.

7) - The management of complex business activities enables the organization's internal staff to focus on tasks which are the most committed to ongoing improvement and innovation in the institution.

8) -Outsourcing makes capital available and increases the institution's knowhow in the short-term, meaning there is no need to immediately train employees. Therefore, the organization has additional time to train and recycle staff, which enables new challenges within the organization to be undertaken without the time pressures posed by the need to take on new tasks without being adequately prepared to do so.

9) -Outsourcing creates a philosophy of teamwork with the outsourcing company, promoting the philosophy of sharing risks, but in a controlled manner, since the outsourced company will eventually be requested to provide clear results. If these same services were to be provided internally and in the hypothetical case that the objectives were not to be reached, there would be no penalty of any type.

10) - In many cases, outsourcing involves an injection of short-term capital in the institution since the company takes charge of the monthly costs of external employees. Therefore if the institution has drafted a payment plan for work performed, it may have cash available for a certain period of time which may be used for other projects requiring capital in this institution.

\section{Conclusions}

-Outsourcing gives rise to the building of a relationship based on association, sharing risks and seeking common outcomes which extend beyond lowering costs.

- In many cases, outsourcing may not be solution for problems arising in information units, since given the time or economic framework of certain activities, simple subcontracting may be more profitable than establishing outsourcing links.

-Outsourcing alone does not improve the productivity and performance of information units. It requires an effort to adapt and to work jointly with other organizations. Also, it is necessary for the institution to be prepared to change the way it works and to be willing to accommodate this type of activity.

-The assessment of the costs (efficiency), time and effectiveness (quality) of the outsourced activity should be positive and should be comparable to other services offered by the internal staff of the institution

- The basic or core functions and business of the institution must be known before outsourcing can be carried out or subcontracting of services can be assessed to determine whether they are truly viable not only in economic terms but also in terms of their effect on the organization and the community of users.

- The benefits offered to the organization by the company selected must be known since it will form part of the organization for a reasonable period of time. Accordingly, if the right choice were not to be made, it could lead to the deterioration of the relationships and activity of the center. 


\section{Bibliografía}

Baker, Barry B. "Resource sharing: outsourcing and technical services". En: Technical services quarterly, 1998, v. 16, n. 2, pp. 35-45.

Balagué Mola, Núria. "L'externalització o la flexibilitat de la gestió". En: Item, 2010, n. 28, pp. 4-13.

Benaud, C. L.;Bordeianu, S. Outsourcing library operations in academic libraries: an overview of issues and outcomes. Colorado: Libraries Unlimited, 1998.

Bush, Carmel C.;Sasse, M.;Smith, P. "Toward a new world order: a survey of outsourcing capabilities of vendors for acquisitions, cataloging and collection development services". En: Library acquisitions: practice \& theory, 1994, v. 18, n. 4, pp. 397-414.

Fogerty, James E. "Archival brinkmanship: downsizing, outsourcing, and the records of corporate America". En: American archivist, 1997, v. 60, pp. 44-55.

Garcia-Abril, Carlota. "Outsourcing documental". En: Outsourcing, 2008, pp. 18-22.

Gidron, Gil. Nuevos modelos de gestión empresarial: el outsourcing de procesos de negocios. Madrid: Círculo de Empresarios, 1998.

Hirshon, Arnold. Outsourcing library technical services. New York: Neal-Schuman, 2007.

Horestein, Bonnie. "Outsourcing copy cataloging at Adelphi University libraries". En: Cataloging \& classification quarterly, 1999, v. 28, n. 4 , pp. 105-116.

Howarth, Lynne C. "The role of the paraprofesional in technical services in libraries". En: Library trends, v. 46, n. 3, pp. 526-539.

Lara Navarra, Pablo;Martínez Usero, José Angel. "Outsourcing documental: organización de futuro". En: VII Jornadas españolas de documentación, 2000, pp. 49-55.

Ogburn, Joyce L. "An introduction to outsourcing". En: Library acquisitions: practice \& theory, 1994, v. 18, n. 4, pp. 363-366.

Peso Navarro, Emilio. Manual de outsourcing informático: análisis y contratación. Madrid: Díaz de Santos, 2000.

Reuvid, Jonathan;Hinks, John. Managing business support services: strategies for outsourcing \& facilities management. London: Kogan Page, 2008. 